\title{
PERIPHERAL NERVE INVOLVEMENT AND SEVERITY OF MOTOR DISORDER IN PARKINSON'S DISEASE: A CORRELATIONAL STUDY
}

\author{
Zuzana Chovancova*, Petr Kanovsky, Jaroslav Dufek, Martin Nevrly, Pavel Otruba
}

\author{
Department of Neurology, Faculty of Medicine and Dentistry, Palacky University Olomouc, and University Hospital Olomouc \\ Center for the Diagnosis and Treatment of Neurodegenerative Diseases, Czech Republic \\ e-mail: zuzana.chovancova@fnol.cz
}

Received: Sepember 22, 2008; Accepted: November 10, 2008

Key words: Parkinson's disease/Polyneuropathy/Electromyography/Correlation

Background: The aim of thisstudy was to test the hypothesis that there is concomitant peripheral nerve involvement in patients suffering from neurodegenerative disorders by correlating motor and peripheral nerve involvement in Parkinson's disease.

Methods and results: A total of 23 patients suffering from Parkinson's disease diagnosed strictly according to the UKPDBB criteria were examined. The group comprised 14 males (mean age: 57 years, mean age at onset: 51 years, mean duration of disease: 7 years, mean duration of dopaminergic treatment: 4 years) and 9 females (mean age: 67 years, mean age at onset: 63 years, mean duration of disease: 4 years, mean duration of dopaminergic treatment: 1 year).

Conclusion: Polyneuropathy was clinically present and confirmed using EMG examination in 10 patients (43.5 \%), 5 males and 5 females. This suggests that the neurodegenerative process involves both the central and the peripheral nervous system in Parkinson's patients.

\section{INTRODUCTION}

Parkinson's disease (PD) is a chronic neurodegenerative disorder stemming form a lack of dopamine in the basal ganglia region. The deficit is due to decreased dopamine transport to the striatum via nigrostriatal projections as a result primarily of the apoptotic death of melanin producing cells in the midbrain substantia nigra region.

PDI is also characterized by other morphological and neurochemical changes reflecting gradual progression of the disease. The recent so-called Braak staging system ${ }^{1}$ defines 6 stages of confirmed morphological involvement of the central nervous system during the progression of Parkinson's disease. The 6 stages correlate with the clinical condition as measured by the Unified Parkinson's Disease Rating Scale (UPDRS) and the Hoehn and Yahr Scale. This clinicopathological correlation, mentioned in the seminal work by Braak et al. ${ }^{1}$, is a reliable basis for comparing CNS involvement in vivo and clinical manifestations of Parkinson's disease. In at least 3 stages (3, 4 and 5), the Braak system states that other than nigrostriatal or, more generally, brainstem structures are involved as well. According to Braak et al., the neurodegenerative process in Parkinson's disease also affects other CNS structures than those contained in the corticostriatal, nigrostriatal or olivonigral systems ${ }^{1-4}$.

Other studies published several years ago suggest that in a relatively high percentage of patients suffering from neurodegenerative diseases, both the cortex and peripheral nerve system are affected. . $^{1,5,7}$ Parkinson's disease is where this involvement is most frequently documented. ${ }^{2,4,6,8-11}$ The studies published so far consider the neuro- degenerative process as a common cause of both central and peripheral nervous system involvement ${ }^{8}$. Thus, it would be logical to assume that the level of impairment as indicated by the UPDRS score will also be subject to this, in fact double, correlation, i.e. both correlation with the Braak stage of involvement and correlation with the presence or possibly severity of peripheral nerve system involvement. To verify the hypothesis, the presented correlation study was carried out.

\section{PATIENTS AND METHODS}

In the study, 23 patients suffering from Parkinson's disease were examined. Parkinson's disease was diagnosed according to the United Kingdom Parkinson's Disease Society Brain Bank criteria (UKPDBB) ${ }^{15}$. The group comprised 14 males and 9 females. In males, the mean age was 57 years, mean age at onset 51 years, mean duration of disease 7 years and mean duration of treatment with dopaminergic drugs 4 years. In females, the mean age was 67 years, mean age at onset 63 years, mean duration of disease 4 years and mean duration of dopaminergic treatment 1 year.

Prior to neurophysiological examination, a complete neurological assessment was performed in all patients, including MRI brain scan, autonomic function assessment, and biochemical, blood and cerebrospinal fluid analyses.

Subsequently, all patients underwent electromyography (EMG) examination ${ }^{12,13}$ comprising a nerve conduction study, H-reflex test and needle EMG. All tests were performed using the Keypoint IV $^{\circledR}$ system (Medtronic, Tonstakken, Denmark). 
Table 1. Comparison of the stages of involvement according to the Braak and Hoehn and Yahr scales.

\begin{tabular}{|c|c|}
\hline Braak & Hoehn and Yahr \\
\hline 1 & 0 \\
\hline 2 & 0 \\
\hline 3 & $1-2$ \\
\hline 4 & $2-3$ \\
\hline 5 & $3-4$ \\
\hline 6 & $4-5$ \\
\hline
\end{tabular}

The nerve conduction study measured motor conduction of the tibial and deep peroneal nerves and sensory conduction of the superficial peroneal and sural nerves. The needle EMG assessed the activity at rest, recruitment and interference curve during maximum effort contraction. The EMG data were entered into an electronic database and statistically processed using the StatSoft ${ }^{\circledR}$ software.

\section{RESULTS}

The results are shown in Tables 2-4.

Of the 23 patients examined in the study, ten showed clinical signs of polyneuropathy (decreased tendon and periosteal reflexes in the lower limbs in any distribution, muscular dystrophy, muscle weakness, hypoesthesia or pallhypoesthesia in the lower limbs in any distribution, subjectively reported dysesthesia or paresthesia in the lower limbs in any distribution). This included 5 females (55.5\%) and 5 males $(35.7 \%)$. In total, clinical signs of polyneuropathy were present in $43.5 \%$ of all patients.

Of the 23 patients, signs of polyneuropathy were detected by EMG in 10 cases $(43.5 \%$ ). (Those ten patients had a clinical signs of polyneuropathy). Polyneuropathy was detected in $5(55.5 \%)$ out of the 9 examined females and in $5(35.7 \%)$ of the 14 males. In all cases, these were patients who had at least one of the above-mentioned signs of polyneuropathy present at the time of previous clinical examination. In males with confirmed polyneuropathy, the mean CMAP latency and amplitude were $4.88 \mathrm{~ms}$ and $4.04 \mathrm{mV}$, the mean SNAP latency and amplitude were $3.28 \mathrm{~ms}$ and $5.14 \mathrm{uV}$, and the mean H-reflex latency and amplitude were $33.8 \mathrm{~ms}$ and $1.94 \mathrm{mV}$, respectively. In females with confirmed polyneuropathy, the mean CMAP latency and amplitude were $4.46 \mathrm{~ms}$ and $3.82 \mathrm{mV}$, the mean SNAP latency and amplitude were $2.28 \mathrm{~ms}$ and $4.10 \mathrm{uV}$, and the mean H-reflex latency and amplitude were $31.94 \mathrm{~ms}$ and $1.52 \mathrm{mV}$, respectively.

The involvement was compared using the Hoehn and Yahr Scale and Braak staging system. As a result, nine patients ( 6 males, 3 females) were classified as Braak stage 3 . Of those, in only 1 male patient polyneuropathy was revealed. Thirteen patients ( 7 males, 6 females) were classified as stage 4 , with polyneuropathy being confirmed in 9 of them ( 4 males, 5 females). One male patient without detected polyneuropathy was classified as stage 5. There were no stage 6 patients.

\section{DISCUSSION}

The presence of polyneuropathy in neurodegenerative diseases is a relatively new clinical fact. So far, in most neurodegenerative diseases, polyneuropathy has not been thought to be related to the underlying process. Only in multiple system atrophy (MSA), symmetric polyneuropathy in the lower limbs was considered a symptom supporting the diagnosis of MSA, in particular multiple system atrophy of parkinsonian type (MSA-P).

In this study, polyneuropathy was documented in 10 (43.5\%) patients out of 23 patients suffering from Parkinson's disease, strictly diagnosed according to the

Table 2. Demographic and history data of the studied Parkinson's patients.

\begin{tabular}{|l|c|c|c|c|c|}
\hline & $\begin{array}{c}\text { Number } \\
\text { of patients }\end{array}$ & Mean age & $\begin{array}{c}\text { Mean age } \\
\text { at the onset } \\
\text { of PD }\end{array}$ & $\begin{array}{c}\text { Mean } \\
\text { duration of PD } \\
\text { (years) }\end{array}$ & $\begin{array}{c}\text { Mean duration } \\
\text { of treatment } \\
\text { with L-DOPA } \\
\text { (years) }\end{array}$ \\
\hline Females & 9 & 67 & 63 & 4 & 1 \\
\hline - with EMG-verified PNP & 5 & 69 & 64 & 5 & \\
\hline - without EMG-verified PNP & 4 & 64 & 61 & 5 & 7 \\
\hline Males & 14 & 57 & 51 & 10 & 4 \\
\hline - with EMG-verified PNP & 5 & 50 & 40 & 57 & \\
\hline - without EMG-verified PNP & 9 & 62 & 57 & & \\
\hline
\end{tabular}

Key: $\mathrm{EMG}=$ electromyography

$\mathrm{PD}=$ Parkinson's disease

$\mathrm{PNP}=$ polyneuropathy 
Table 3. CMAP, SNAP and H-reflex latency and amplitude values.

\begin{tabular}{|c|c|c|c|c|c|c|c|c|}
\hline \multirow[b]{3}{*}{ H-reflex } & \multicolumn{4}{|c|}{ Males } & \multicolumn{4}{|c|}{ Females } \\
\hline & \multicolumn{2}{|c|}{$\begin{array}{l}\text { Without EMG signs } \\
\text { of polyneuropathy } \\
(\mathrm{n}=9)\end{array}$} & \multicolumn{2}{|c|}{$\begin{array}{l}\text { With EMG signs } \\
\text { of polyneuropathy } \\
\qquad(\mathrm{n}=5)\end{array}$} & \multicolumn{2}{|c|}{$\begin{array}{l}\text { Without EMG signs } \\
\text { of polyneuropathy } \\
\qquad(\mathrm{n}=4)\end{array}$} & \multicolumn{2}{|c|}{$\begin{array}{l}\text { With EMG signs } \\
\text { of polyneuropathy } \\
\qquad(\mathrm{n}=5)\end{array}$} \\
\hline & $\mathrm{L}$ & $\mathrm{R}$ & $\mathrm{L}$ & $\mathrm{R}$ & $\mathrm{L}$ & $\mathrm{R}$ & $\mathrm{L}$ & $\mathrm{R}$ \\
\hline Latency (ms) & 33.94 & 34.20 & 33.62 & 33.98 & 31.30 & 30.67 & 32.12 & 31.76 \\
\hline Amplitude (mV) & 1.27 & 1.82 & 2.40 & 1.48 & 1.90 & 3.30 & 1.02 & 2.02 \\
\hline \multicolumn{9}{|c|}{ CMAP - tibial nerve } \\
\hline Latency (ms) & \multicolumn{2}{|c|}{4.17} & \multicolumn{2}{|c|}{4.88} & \multicolumn{2}{|c|}{5.00} & \multicolumn{2}{|c|}{4.46} \\
\hline Amplitude (mV) & \multicolumn{2}{|c|}{7.54} & \multicolumn{2}{|c|}{4.04} & \multicolumn{2}{|c|}{5.85} & \multicolumn{2}{|c|}{3.82} \\
\hline \multicolumn{9}{|c|}{ SNAP - sural nerve } \\
\hline Latency (ms) & \multicolumn{2}{|c|}{3.48} & \multicolumn{2}{|c|}{3.28} & \multicolumn{2}{|c|}{3.62} & \multicolumn{2}{|c|}{2.28} \\
\hline Amplitude (uV) & \multicolumn{2}{|c|}{6.65} & \multicolumn{2}{|c|}{5.14} & \multicolumn{2}{|c|}{6.05} & \multicolumn{2}{|c|}{4.10} \\
\hline $\mathrm{SCV}(\mathrm{m} / \mathrm{s})$ & \multicolumn{2}{|c|}{45.10} & \multicolumn{2}{|c|}{34.70} & \multicolumn{2}{|c|}{48.30} & \multicolumn{2}{|c|}{29.50} \\
\hline
\end{tabular}

Key: $\mathrm{L}=$ left
$\mathrm{R}=$ right
CMAP = compound muscle action potential
SNAP $=$ sensory nerve action potential
$\mathrm{SCV}=$ sensory nerve conduction velocity

Table 4. Presence of polyneuropathy in patients classified according to the Hoehn and Yahr Scale.

\begin{tabular}{|c|c|c|c|c|c|c|c|}
\hline \multirow{2}{*}{$\begin{array}{c}\text { Hoehn and } \\
\text { Yahr stage }\end{array}$} & \multicolumn{2}{|c|}{$\begin{array}{c}\text { Number } \\
\text { of patients }\end{array}$} & \multicolumn{2}{c|}{$\begin{array}{c}\text { Polyneuropathy } \\
\text { Males }\end{array}$} & \multicolumn{2}{c|}{$\begin{array}{c}\text { Polyneuropathy } \\
\text { Females }\end{array}$} & $\begin{array}{c}\text { Braak } \\
\text { stage }\end{array}$ \\
\cline { 2 - 8 } & males & females & yes & no & yes & no & \\
\hline 1.0 & 1 & 0 & 1 & 0 & 0 & 0 & 3 \\
\hline 1.5 & 2 & 2 & 0 & 2 & 0 & 2 & 3 \\
\hline 2.0 & 3 & 1 & 0 & 3 & 0 & 1 & 3 \\
\hline 2.5 & 3 & 4 & 2 & 1 & 3 & 1 & 4 \\
\hline 3.0 & 4 & 2 & 2 & 2 & 2 & 0 & 4 \\
\hline 3.5 & 0 & 0 & 0 & 0 & 0 & 0 & 5 \\
\hline 4.0 & 1 & 0 & 0 & 1 & 0 & 0 & 5 \\
\hline 4.5 & 0 & 0 & 0 & 0 & 0 & 0 & 6 \\
\hline 5.0 & 0 & 0 & 0 & 0 & 0 & 0 & 6 \\
\hline
\end{tabular}

UKPDBB criteria. Surprisingly, the proportion was higher than that in the study by Pramstaller et al. focused on MSA patients. ${ }^{14}$ This probably means that, similar to the authors of previous studies who considered the underlying pathological process in MSA to be the cause of polyneuropathy as well, neurodegenerative processes (in a broad sense) may be considered the cause of polyneuropathy in our group of Parkinson's patients. The mechanism of peripheral neurodegeneration has not been explicitly described as yet which is understandable given the fact that neurodegeneration of the CNS is also far from being completely explained.

Another aim of the study was to correlate peripheral nerve involvement with the Braak staging system outcomes. Although many neuropathologists object to Braak's concept of vertical progression of neurodegeneration, it is considered a plausible explanation of the gradual progression of the clinical symptomatology of 
Parkinson's disease by most of them. Similarly, the correlation between the Hoehn and Yahr stage of clinical involvement and the Braak stage is undoubtedly a construct continuously verified since the seminal work by Braak et al. was published in 2003. From a heuristic point of view, however, this is an extremely important shift in understanding the interrelations between morphological changes in the CNS and clinical symptomatology in the specific time domain of the development of a pathological process. Therefore, extraordinary attention should be paid to the fact that polyneuropathy was detected in 9 out of 13 (i.e. nearly $70 \%$ ) patients with clinical involvement corresponding to Braak stage 4 . This would mean that neurodegenerative process in the peripheral nervous system of a particular individual begins only after the same process in the CNS reaches a certain degree of progression. In other words, the extent of apoptosis and the existing neurodegenerative process increases to a point that besides central structures, peripheral structures are affected as well. Finding more significant peripheral nerve involvement in patients with more severe Parkinson's disease would surely support this preliminary hypothesis. Therefore, more research and longer observation of a larger group of patients are needed, including individuals suspected of having stages 5 and 6 involvement. That is, more patients with the most advanced form of Parkinson's disease, with clinical involvement equivalent to stages 4 through 6 of the Hoehn and Yahr Scale.

\section{REFERENCES}

1. Braak H, Del Tredici K, Rüb U, et al. Staging of brain pathology related to sporadic Parkinson's disease. Neurobiology of Aging 24, 2003: 197-211.
2. Abbruzzese G, Pigullo S, Schenone A, Bellone E, Marchese R, Di Maria E, Benedetti L, ciotti P, Nobbio L, Bonifati V, Ajmar F, Mandich P. Does parkin play a role in the peripheral nervous system? A family report. Mov Disord 2004; 18: 978-981.

3. Rodolico C, Toscano A, De Luca G, Mazzeo A, Di Leo R, Baldari S, Girlanda P, Vita G. Peripheral neuropathy as the presenting feature of multiple system atrophy. Clin Autonom Res 2001; 11:63.

4. Taly AB, Mutane UB. Involvement of peripheral nervous system in juvenile Parkinson's disease. Acta Neurol Scand 1992; 85: 272-275.

5. Abele M, Schulz JB, Burk K, Topka H, Dichgans J, Klockgether T. Nerve conduction studies in multiple system atrophy. Eur Neurol 2000;43: 221-223.

6. Becker G, Muller A, Braune S, Buttner T, Benecke R, Greulich W, Klein W, Mark G, Rieke G, Thumler R. Early diagnosis of Parkinson's disease. J Neurol 2002; 249 (Suppl.3): 40-48.

7. Geser F, Wenning GK. The diagnosis of multiple system atrophy. J Neurol. 2006; 253 (suppl.3).

8. Hoehn MM, Mahr MD. Parkinsonism: onset, progression and mortality Neurology 1967, 17: 427-42.

9. Chovancová Z, Kaňovský P, Nestrašil I, Dufek J. Peripheral nerves injury in the central nervous system degeneration: pilot study (abstract). Movement Disorders, Vol 21, Suppl. 15, 2006, pp. S362-S363.

10. Nevrlý M, Vranová H, Ressner P, Nestrašil I, Kaňovský P. Effect of levodopa and entacapone treatment on plasma homocysteine level in Parkinson disease: pilot study. (abstract) Movement Disorders, Vol 21, Suppl. 15, 2006, pp. S545.

11. Tolosa E, Wenning G, Poewe W. The diagnosis of Parkinson's disease. Lancet Neurol. 2006; 5: 75-86

12. Dumitru D, Amato AA, Zwarts MJ. Electrodiagnostic medicine. Second edition. Hanley and Belfus: Philadelphia 2002, s. 921-923.

13. Hallett $M$ ad. Handbook of Clinical Neurophysiology, Vol 1, Movement disorders, 1st Edition, Philadelphia, Elsevier 2003: 7-19

14. Pramstaller PP, Wenning GK, Smith SJ, Beck RO, Quinn NP, Fowler CJ. Nerve conduction studies, skeletal muscle EMG, and sphincter EMG in multiple system atrophy. J Neurol 1985; 42 : 695-696.

15. Hughes AJ, Daniel SE, Kilford L, Lees AJ et all. Accuracy of clinical diagnosis of idiopathic Parkinson's disease: a clinico-pathological study of 100 cases. J Neurol Neurosurg Psychiatry. 1993 Aug; 56(8):938-9. 